\title{
Statyba
}

\section{COMPRESSION OF THE CLAY SOILS OF NON- DESTRUCTED AND DESTRUCTED STRUCTURE}

\section{A Alikonis}

To cite this article: A Alikonis (1997) COMPRESSION OF THE CLAY SOILS OF NON-DESTRUCTED AND DESTRUCTED STRUCTURE, Statyba, 3:11, 61-69, DOI: 10.1080/13921525.1997.10531355

To link to this article: https://doi.org/10.1080/13921525.1997.10531355

曲 Published online: 26 Jul 2012.

Submit your article to this journal

山 Article views: 58 


\section{СЖИМАЕМОСТЬ ГЛИНИСТОГО ГРУНТА НЕНАРУШЕННОГО И НАРУІЕННОГО СЛОЖЕНИЯ}

\section{А. Аликонис}

\section{1. Внеденис}

Грунт состоит из твердых частиц и пгор, которые полиостью или частично заполнены водой ишт воздухом. Деформации частиц, воды и газа, возникающие из-за небольших напряжений сжатия в основания зданий, при решснии пнженерных задач не уиттываются. Принимается, что изменение объсма грунта при сжатии происходит из-за изменения объема пор от уплотнения.

В процессе образования глинистьх грунтов между тастицами возникли водно-коллондные и другие связи, прндающце грунту дополнительную прочность, называемую структурной прочностью грунта $\sigma_{c m p}$.

При давлении, ие прсвышающем структурnoï прочності $\left(\sigma<\sigma_{c m p}\right)$, уплотнение не ıронсходит, так как давление воспринимается водно-коллогдными и кристаллизационными связями. Уплотнение грунта пронсходит после разрушения связей.

Структурігую прочность грунта можно онределить по результатам испытания грунта в одометрах (по Н.А.Цытовнчу), в приборах трехосного сжатия (по Е.И.Медкову), при вдавливаниш нггампа в натурньх условиях залегания гругта нии другими способами.

Дсформации уплотисния глинистого гругта естествениог сложения и $\mathrm{c}$ нарушенными структурными связями пронсходят по-разному. Как показывают эксперимситальные исследования лимнолапиалынх глни в компрессионных прнборах, их сжимасмость разпитается в цва раза и болісс [1]

Исследозапиями пшмноглациалынь глин [1] установлело, тто ири одниаковом значении натального коэффицценга пористости естест- вениого и парушенного сложения $e_{0}$ уплотнение грунта происходит по-разному и при одинаковом давлении зиачения параметров сжимаемости оказываются разными. Если сжимасмость оценить коэффициентом относительной сжимаемости, то для гругта нарушенного сложения при той же нагрузке он больше, чем для грунта ненарушенного сложения.

В строительной практике возникает проблема сжимаемости грунта иенарушенного и нарушенного сложения при возникших перебоpax грунта, при возведении котлованов для зданий и траншей подземньх коммуникаций. Действовавшие ранее строительные нормы и правила CHuII III-E.1-62 [2] во избежание неравномерных оседаиий требовали случайные переборы при земляных работах заполиять тем же грунтом и уплотнять его цо естественной плотности.

Результаты эксперіментальных исследований и строительная практика показали, что гругт нарушенного сложения, которым заполняются переборы при земляньх работах, хотя и уплотнен до плотности естествснного грунта, деформируется больше, чем естсственный грунт.

Действующие в настоянее время нормы и правила СНиП [3] осторожнес Іодходят $\mathbf{k}$ уплотнению грунта в случайных переборах при зсмляпцх работах. В гих сохрапшіось требованис восполнгть переборы в местах устройства фуцдаментов и укладки трубопроводов местным гругтом с уплотненисм его цо плотности груігта естественного сложения основания. Оцнако при гтубине переборов, превынаюцей $50 \mathrm{cм}$, способ заполнения должсн быть согласован с просктной организацией. 
Для определения степени упютнения грунта нарушенного сложения, позволяющего получить сжимаемость под нагрузкой, равной сжимаемости гругта ненарушенного сложения, необходимо провести специалыне исследования того же грунта ненарушенной и нарушенной структуры.

Теоретические и экспериментальные исследования показали, что можно получить зависимость для определения началыного коэффициента пористости грунта иарушенного сложения, при котором сжимаемость для заданного давления будст приблизительно такой же, что и для грунта ненарушенного сложения.

\section{2. Теоретическос опрсделение зачсния начального}

\section{коэффициента пористости}

Компрессионная зависимость в полулогарифмической системе координат на участке $\mathrm{BC}$ (рис. 1) будет прямой линией

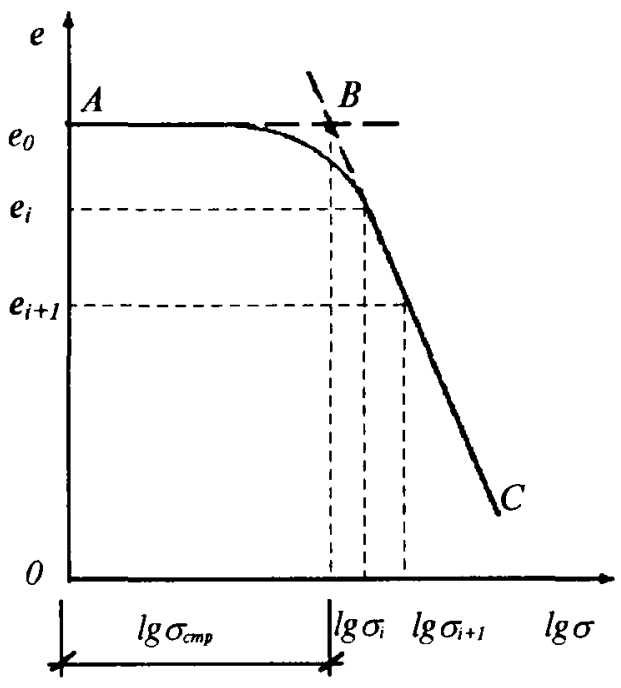

Рис. 1. Компрессионная кривая глинистого грунта, обладающего структурной прочностью, в полулогарифмической системе координат

Fig 1. Compression curves of structurally rigid clay soils in a semi-logarithmic scale

Структурную прочность по такой компрессионной кривой можно приблизительно определить по перессчению продолжения прямой $\mathrm{BC}$ с горизогталыной линией $\mathrm{AB}$, соответствующей зиачению начального коэффициенга пористости $e_{0}$ [4]. Тот же грунт нарупенного сложения (тицательно перемятый) не будет обладать структурной прочностью. Однахо нельзя утвержлать, что при перемятии глинистоюо грунта полностью исчезают структурные связи. Часть структурных связей остается и составляет небольшую долю от первоначальной структурной ирочности. При компрессионном сжатии перемятого глинистого гругта на начальном участке компрессионной кривой в полулогарифмической системе координат появляется неболыной горизонтальный участок $\mathrm{AB}$ (рис. 2). По сравнению со значением структурной прочности глинистого грунта естественного сложения оставшаяся структурная прочность после перемятия груита составляет весьма небольную долю [5].

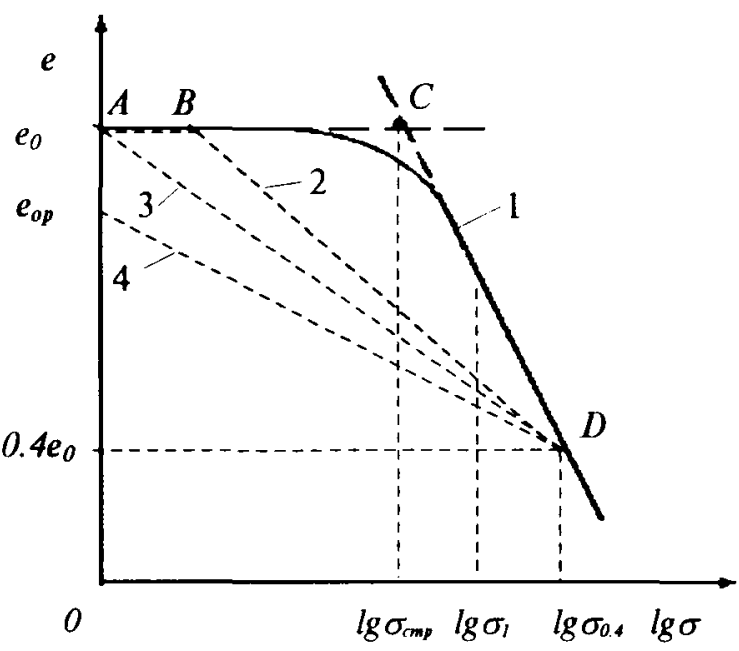

Рис. 2. Компрессионные кривые глинистого грунта, обладающего структурной прочностью:

1 - естественный груит; 2, 3, 4 - тот же грунт нарушенной структуры (перемятый)

Fig 2. Compression curves of structurally rigid clay soils: 1 - natural soils; 2, 3, 4 - soils of destructed structure

Поэтому при решении нижснерных задач можно принять, что компрессиониая кривая грунта нарушенного сложения в полулогарифмической системе координат начинается от точки А (рис. 2). При давлении $\sigma<\sigma_{c m p}$, менышем, чем структурная прочность гругта, пагрузка воспринимается водно-коллоидными и кристаллизационинми связями, и деформации унлотнения практитески не развиваются (рис. 2, 1 кривая). После разрушенния этих связей при $\sigma>\sigma_{c m p}$ происходит унлотнение гругта. Иначе 
ведет себя грунт при его нарушенной структуре: он деформируется практически от начала приложения первой ступени нагрузки (рис. 2, 3 линия).

Таким образом, глинистый грунт ненарушенной и нарушенной сгруктуры уплотняется по-разному, но теоретически, в конечном результате, при большом давлении в обоих случаях уплотнение одинаково, когда $e=0$. Исследования грунтов ненарушенной и нарушенной структуры свидетельствуют о том, чго компрессионные кривые таких грунтов в полулогарифмической системе координат соприкасаются одна с другой при $0,4 e_{0}[5], 0,42 e_{0}[6]$ или при $e_{\text {мин }}$ [7], и дальнейшее уплотнение груіта протехает практически одинаково.

При одинаковом давлепии глинистый грунт ненарушенного и иарушенного сложения будет иметь разные значения показателей сжимаемости, например, величину относительной сжимаемости. Если грунт нарушенного сложения дополнительно уплотнить, т. е. создать плотность, начальный коэффициент пористости $e_{o p}$ которого меньше, чем начальный хоэффициент пористости грунта ненарушенного сложения $e_{0}$ (рис. 2, линия 4), то при дальнейшем увеличении нагрузки получим такое давление, при котором значения относительной сжимаемости практически одинаковы.

Для практических целей задача может быть сформулирована так: кахим должаго быть значение начального коэффициента пористости грунта нарушенного сложения, чтобы при соответствующей нагрузке на грунт получить одинаковую осадку слоя грунта нарушенного и ненарушенного сложения. Принимая, что в любом случае компрессионные кривые глинистого грунта с нарушенной и ненарушенной структурой соприкасаются при $0,4 e_{0}[5]$, можем записать уравнение осадки слоя грунта с ненарушенной структурой [8].

$$
S=H \frac{C_{c}}{1+e_{0}}\left(\lg \sigma_{1}-\lg \sigma_{c m p}\right),
$$

где $S$ - осадка слоя грунта естественного сложепия; $H$ - толишна слоя грунта; $C_{c}-$ коэффициент компрессии; $e_{0}$ - начальный коэффициент пористости; $\sigma_{1}$ - давление на грунт; $\sigma_{c m p}$ - структурная прочность грунта.

Такого же вида зависимость можно записать и для расчета осадки слоя грунта нарушенной структуры (рис. 2).

$$
S_{/}=H_{/} \frac{C_{c}{ }^{\prime}}{1+e_{o p}} \lg \sigma_{1},
$$

где $S_{l}$ - осадка слоя грунта нарушенной структурк; $H_{/}$- толщина слоя грунта; $C_{c}^{\prime}-$ коэффищиент компрессии; $e_{\text {op }}$ - начальный

коэффициент пористости; $\sigma_{1}$ - давление на грунт.

Принимаем, что толщина слоя грунта ненарушенного сложения $H$ равна толшине слоя грунта нарушенного сложения $H_{/}$.

Для определения давления, при котором осадки слоя грунта толциной $H$ для нарушенного и ненарушенного сложения будут одинаковыми, сравниваем формулы (1) и (2) и получаем выражение:

$$
H \frac{C_{c}}{1+e_{0}}\left(\lg \sigma_{1}-\lg \sigma_{c m p}\right)=H_{/} \frac{C_{c}{ }^{\prime}}{1+e_{o p}} \lg \sigma_{1} .
$$

Так как $H=H_{/}$, следует

$$
\frac{C_{c}}{1+e_{0}}\left(\lg \sigma_{1}-\lg \sigma_{c m p}\right)=\frac{C_{c}{ }^{\prime}}{1+e_{o p}} \lg \sigma_{1} .
$$

Выражение (4) является уравнением для расчета $e_{o p}$.

После математических преобразований получаем несколько разннх видов выражения (4).

$$
\begin{gathered}
\frac{C_{c} \lg \sigma_{1}-C_{c} \lg \sigma_{c m p}}{1+e_{0}}=\frac{C_{c}{ }^{\prime} \lg \sigma_{1}}{1+e_{o p}}, \\
\left(C_{c} \lg \sigma_{1}-C_{c} \lg \sigma_{c m p}\right)\left(1+e_{o p}\right)=C_{c}{ }^{\prime} \lg \sigma_{1}\left(1+e_{0}\right),(6) \\
C_{c} \lg \sigma_{1}-C_{c} \lg \sigma_{c m p}+C_{c} \lg \sigma_{1} e_{o p}-C_{c} \lg \sigma_{c m p} e_{o p}= \\
=C_{c}{ }^{\prime} \lg \sigma_{1}+C_{c}{ }^{\prime} \lg \sigma_{1} e_{0} .
\end{gathered}
$$

Коэффициент компрессии гругта ненарушенного сложения $C_{c}$ как постоянную величину определяем по прямому участку хомпрессионной кривой в полулогарифмической системе координат (рис. 1).

$$
C_{c}=\frac{\boldsymbol{e}_{i}-\boldsymbol{e}_{i+1}}{\lg \sigma_{i+1}-\lg \sigma_{i}} .
$$


Коэффициент компрессии грунта с нарушенной структурой определяем по компрессноному графику 4 , рис. 2, в полулогарифмической системе координат.

$$
C_{c}^{\prime}=\frac{e_{o p}-e_{0,4}}{\lg \sigma_{0,4}},
$$

где $e_{o p}$ - начальный коэффициент пористости грунта нарушенной структуры; $e_{0,4}-$ коэффициент пористости, соответствуюций $e_{o} \times 0,4 ; \lg \sigma_{0,4}-$ логарифм давления, соответствуюший коэффициенту пористости $\boldsymbol{e}_{0,4}$.

Дальнейшее преобразование формулы (7) проводим, подставляя в нее выражение $C_{c}^{\prime}$ из (9), а $C_{c}$ оставляем прежним, так как в выражении (8) все величины известны и легко определимн по хомпрессионной кривой в полулогарифмической системе координат.

Подставляя значения $C_{c}^{\prime}$, получим

$C_{c} \lg \sigma_{1}-C_{c} \lg \sigma_{c m p}+C_{c} \lg \sigma_{1} e_{o p}-C_{c} \lg \sigma_{c m p} e_{o p}=$
$e_{o p}-e_{0,4} e_{o p}-e_{0,4}$

$=\frac{e_{o p}-e_{0,4}}{\lg \sigma_{0,4}} \lg \sigma_{1}+\frac{e_{o p}-e_{0,4}}{\lg \sigma_{0,4}} \lg \sigma_{1} e_{0}$,

$C_{c} \lg \sigma_{1}-C_{c} \lg \sigma_{c m p}+C_{c} \lg \sigma_{1} e_{o p}-C_{c} \lg \sigma_{c m p} e_{o p}=$
$=\frac{\lg \sigma_{1} e_{o p}-\lg \sigma_{1} e_{0,4}}{\lg \sigma_{0,4}}+\frac{\lg \sigma_{1} e_{o} e_{o p}-\lg \sigma_{1} e_{o} e_{0,4}}{\lg \sigma_{0,4}}$

$C_{c} \lg \sigma_{1} \lg \sigma_{0,4}-C_{c} \lg \sigma_{c m p} \lg \sigma_{0,4}+$

$+C_{c} \lg \sigma_{1} e_{o p} \lg \sigma_{0,4}-C_{c} \lg \sigma_{c m p} e_{o p} \lg \sigma_{0,4}=$

$=\lg \sigma_{1} e_{o p}-\lg \sigma_{1} e_{0,4}+\lg \sigma_{1} e_{o} e_{o p}-\lg \sigma_{1} e_{0} e_{0,4}$,

$C_{c} \lg \sigma_{1} \lg \sigma_{0,4}-C_{c} \lg \sigma_{c m p} \lg \sigma_{0,4}+\lg \sigma_{1} e_{0,4}+$

$+\lg \sigma_{1} e_{0} e_{0,4}=\lg \sigma_{1} e_{o p}+\lg \sigma_{1} e_{0} e_{o p}-$

$-C_{c} \lg \sigma_{1} e_{o p} \lg \sigma_{0,4}+C_{c} \lg \sigma_{c m p} e_{o p} \lg \sigma_{0,4}$,

$C_{c} \lg \sigma_{1} \lg \sigma_{0.4}-C_{c} \lg \sigma_{c m p} \lg \sigma_{0.4}+\lg \sigma_{1} e_{0.4}+$

$+\lg \sigma_{1} e_{o} e_{0,4}=e_{o p}\left(\lg \sigma_{1}+\lg \sigma_{1} e_{o}-\right.$

$\left.-C_{c} \lg \sigma_{1} \lg \sigma_{0,4}+C_{c} \lg \sigma_{c m p} \lg \sigma_{0,4}\right)$,

$\frac{C_{c} \lg \sigma_{1} \lg \sigma_{0,4}-C_{c} \lg \sigma_{c m p} \lg \sigma_{0,4}+\lg \sigma_{1} e_{0,4}+\lg \sigma_{1} e_{o} e_{0,4}}{\lg \sigma_{1}+\lg \sigma_{1} e_{o}-C_{c} \lg \sigma_{1} \lg \sigma_{0,4}+C_{c} \lg \sigma_{c m p} \lg \sigma_{0,4}}$.

$e_{o p}=\frac{C_{c} \lg \sigma_{0,4}\left(\lg \sigma_{1}-\lg \sigma_{c m p}\right)+e_{0,4} \lg \sigma_{1}\left(1+e_{0}\right)}{\lg \sigma_{1}\left(1+e_{0}\right)+C_{c} \lg \sigma_{0,4}\left(\lg \sigma_{c m p}-\lg \sigma_{1}\right)}$.
Коэффищиент компрессии $C_{c}$ ненарушенного грунта также можно найги из выражения

$$
C_{c}=\frac{e_{0}-e_{0,4}}{\lg \sigma_{0,4}-\lg \sigma_{c m p}},
$$

где $e_{O}$ - начальный коэффициент пористости; $e_{0,4}$ - коэффициенг пористости, соответствуюший точке перссечения компрессионнwх кривых ненарушенного If нарушенного сложения в полулогарифмической системе координат, $e_{0,4}=e_{0} \times 0,4 ; \sigma_{0,4}-$ давление, соответствующее коэффициенту пористости $e_{0,4} ; \sigma_{c m p}-$ структурная прочность грунта.

Подставив в выражение (17) значение $C_{c}$, найденное по формуле (8), можем записать:

$$
\begin{gathered}
C_{c}\left(\lg \sigma_{0,4}-\lg \sigma_{c m p}\right)=e_{o}-e_{0,4}, \\
C_{c} \lg \sigma_{0,4}=C_{c} \lg \sigma_{c m p}+e_{o}-e_{0,4},
\end{gathered}
$$

откуда

$$
\lg \sigma_{0,4}=\frac{\mathrm{C}_{\mathrm{c}} \lg \sigma_{c m p}+e_{0}-e_{0,4}}{C_{c}} .
$$

Теоретические решения для определения начального коэффищиегта пористости грунта нарушенной структуры, при котором осадки слоя грунта нарушенюой и ненарушенной структуры были приблизительно одинаковыми, проверялись экспериментально по результатам компрессиониьх исследований лимноглациальной глины ненарушенного и нарушенного сложения.

\section{3. Эксперименталыные и расчетные значения коэффнциентов пористости}

Экспериментально-теоретические решения проверялись на лимноглациальной глине как нормально уплотненном В природных условиях залегания гругте.

Лимноглациальньх глинистьх отложений неоплейстоценового возраста на территории Литвы доволыю много (око.то 10\% всей площади) [9]. Особую роль в сжимаемости этих глин играют структурные связи, которые придают породе допотнительную механическую прочность. Аналогиное явление можно заметить при испытаниц на сжатие образцов пород с 
ненарушениым и иарушенным сложением. $B$ случае глинистых пород нарушение соответствуюших связей между частицами может привести К потере прочности и $\mathrm{K}$ значительному росту сжимаемосги пород под нагрузкой.

Структурныс связи лимноглациалыны глин должны рассматриваться как общее физическое состояние, которое зависит от минерального состава глин, содержания электролитов в водной среде, времени структурообразования, физикомеханических процессов, других компонентов и формируется в результате взаимодействия этих компонентов с определениог тина связями между ними. Это обуславливает необходимость пнтегральной оценки фнзическото состояния глинистой породы, которая должна отражать суммарный итог внешних ин внутренних процессов, определяющих ее формирование. Исследованицми условий образования лимноглациальпих отложений установлен смешанный характср структурных связей, т.е. наряду с хоагуляционно -тиксотропными связями (которые придают глинам определенную структурную прочность) с самого начала процесса осадкообразования в этіх отложениях возникают и конденсациониокристаллизационные (по П.Я.Ребиндеру) связи.

Отмечая сравнительно значительную сте-пень изменения глинистых пород при осадкообразовании, важто подчеркнуть, что далеко не все они цостигают болыной плотности и прочности. Это объясняется тем, что струкгурные связи придают породам те пли иные свойства, то или иное физическое состояние.

Ция изучсния влияния сложения (наруненного и пенарупениог) на деформапионные свойства лимнолациальны глии Јитвы нами блши ироведелы специальные компрессионные оныты с микрослонстыми образцами.

Образцы нарунениого слгжения подготавливались тицатетьным черемsгием пород при coxpaнспи естествсниӧ̈ вјажности. Из 70 компресснопнх опнтов нарушениого и ненарушениого сложения были вылелены отдельные группы с пачальным коэффицислтом пористости $e_{0}=1,00-0,950, e_{0}=0,950-0,900$, $\mathfrak{e}_{0}=0,900-0,8,50$ in $\boldsymbol{e}_{0}=0,800-0,750$
Сравнения изменений коэффициента пористости с ростом нагрузки показали зависимость влияния нарушения естественного сложения на сжимасмость от начального коэффициента пористости. $\mathrm{C}$ ростом значений начального коэффициента пористости увеличивается разница между коэффициентами пористости нарушенного и пенарушенного сложепия, хотя давление увеличивается одинаково.

Этот вывод подтверждается и при анализе значений относителыного сжатия и коэффициента сжимаемости в зависимости от начального коэффициента пористости образцов нарушенпого и ненарушенюоо сложения.

Различная сжимаемость глин иарушенного и генарушенного сложения при обыгно принятых в строительной практике нагрузках объясляется иарушением природинд связей, а замеченное уменьшение разницы в сжимаемости с уменьшением величины начального коэффициента пористости указывает на умсиьшение тувствительности с увеличением плотности.

Анализ зависимости относительного сжатия от начального коэффициента пористости $\left(e_{0}\right)$ при вертикальном давлении 0,2 МПа показал, тто разница между относителыным сжатием образцов глины нарушениого и ненарушениого сложения увеличивается с увеличепием зиатений натального коэффициегта пористости.

Из результатов проведенных компрессионпьх испытаний гимноглачиалыюй глины чарупениог и ненарушениого сложения бцли выделены группы по началыному коэффициснту пористости гругта нарупениого и ненарушенного сложения, имеюнце одинаковый коэффициент сжатия при давлении 0,2 МПа. Полученные результаты представлены в табл. 1.

С использованием результатов компрессионньх испнганий лимноглациальной глины пенарупенного сложения по формуле (15) были расситганы коэффицие іты пористости глин нарупеніого сложения $e_{o p}$. Сжимасмость названия глии при давлении 0,2 МПа та же, что и у гругта ненарунениого сложения. Результаты расчета привелены в табл. 2. 
Таблица 1. Начацыные коэффициенты нористости ири одинаконом относительном сжатини давлении 0,2 $\mathrm{MITa}$

Table 1. The initial porosity factors to obtain equivalent relative compression under the loading of (0.2 MPa

\begin{tabular}{|c|c|c|c|c|c|c|c|}
\hline & \multicolumn{7}{|c|}{ Значения иачалыных коэффициентов пористости } \\
\hline $\begin{array}{l}\text { Ненарушениос } \\
\text { сложение грунт, eo }\end{array}$ & 1,000 & 0.900 & 0,800 & 0,750 & 0,700 & $0,6.50$ & 0,600 \\
\hline $\begin{array}{l}\text { Нарушенное } \\
\text { сложение груита, } e_{o p}\end{array}$ & 0,780 & 0,750 & 0,700 & 0,650 & 0,620 & 0,600 & 0,577 \\
\hline
\end{tabular}

Таблица 2. Значения коэффициентов пористости и коэффициентов компрессии (ири давлении 0,2 МПа)

Table 2. Assessment of porosity and compression factors under the loading of $0,2 \mathrm{MPa}$

\begin{tabular}{|c|c|c|c|c|}
\hline $\begin{array}{c}\text { Началыный } \\
\text { коэффициент } \\
\text { пористости } \\
\text { ненарушенного } \\
\text { сложения, } e_{0}\end{array}$ & $\begin{array}{c}\text { Начальный } \\
\text { коэффициент } \\
\text { пористости } \\
\text { нарушенного } \\
\text { сложения, } e_{o p}\end{array}$ & $\begin{array}{c}\text { Коэффиниент } \\
\text { компрессии } \\
\text { ненарушенного } \\
\text { сложения, } C_{c}\end{array}$ & $\begin{array}{c}\text { Коэффициснт } \\
\text { компрессий } \\
\text { нарушенного } \\
\text { сложения, } C_{c}^{\prime}\end{array}$ & $C_{c} / C_{c}^{\prime}$ \\
\hline 0,975 & 0,782 & 0,0872 & 0,0577 & 1,5 \\
\hline 0,975 & 0,766 & 0,076 & 0,0512 & 1,48 \\
\hline 0,875 & 0,711 & 0,125 & 0,0843 & 1,48 \\
\hline 0,775 & 0,620 & 0,036 & 0,0238 & 1,5 \\
\hline 0,688 & 0,566 & 0,114 & 0,0786 & 1,44 \\
\hline
\end{tabular}

В табл. 2 приведено расчетное значение начального коэффициегта порнстости $e_{\text {op }}$, до которого надо уплотнить лимноглациальный грунт нарушенного сложения, чтобы получить одинаковую осадку слоя грунта ненарушенного сложения ири давлени 0,2 МПа для соответствующего значения началыого коэффицисита порнстости групта ненарушеннопо сложения.

В табл. 2 также приведени те же знатения коэффнциетов пористости, что и при исследовании лимночациалыюой глины в компресснонных ириборах. Сравнение экспериментаниых и расчетных значений иачальнык козффициентов пористости грунта пенарушенного и нарушенного сложения, при которых и давлении 0,2 МПа получаем одинаковыс дерормации, приведены в табл. 3.

Сравнение растетных и экспсриментальны значений начальньх коэффициелтов нористости грунта нарушенного сложения, при которых получаем одинаковые деформации гругта нарушенного и ненарушенного сложения, показывает (табј. 3), что разиица межлу иими колеблется в небольиих прслелах - лля давления 0,2 МПа от 2 до $10 \%$.

Таблица 3. Расчетные и эксперименталыне зиачения коэффициептов пористости $e_{\text {ор }}$ Table 3. Calculated and cxperimentally obtained assessment of porosity factors $e_{o p}$

\begin{tabular}{|c|c|c|c|c|}
\hline \multirow[b]{2}{*}{$\begin{array}{l}\text { Начальный коэффициент пористости } \\
\text { грунта ненарупениого сложения } e_{0}\end{array}$} & \multicolumn{4}{|c|}{ Значения начальных коэффициентов пористости $е$ и } \\
\hline & 0,975 & 0,875 & 0,775 & 0,688 \\
\hline $\begin{array}{l}\text { Расчетный началыный коэффициент } \\
\text { пористости грунта нарушенното } \\
\text { сложения } e_{o p}\end{array}$ & 0,782 & 0,711 & 0,620 & 0,566 \\
\hline $\begin{array}{l}\text { Экспсриментальный началыпый } \\
\text { коэффициент пористости групта } \\
\text { нарупениого сложения } e_{o p}\end{array}$ & 0.765 & $0,72.5$ & 0,675 & 0,610 \\
\hline
\end{tabular}


Результаты, приведенные в табл. 1 и 2, показывают, что с уменынением значения начального коэффициегта пористости уменьшается разница между начальными значегиями коэффициента пористости естественного и нарушенного сложения, т.е. между значсниями $e_{0}$ и $e_{\text {op }}$. Эта разница меныне для экспериментальньх результатов и больше для растетньх. Для экспериментальных результатов она меняется в диапазоне начального козффициента пористости грунта естественното сложения от 1,000 до 0,700 соответственно от 0,220 до 0,080 , a для расчетных результатов в диапазоне начального коэффициента пористости от 0,975 до 0,688 соответственно от 0,193 до 0,122 . Уменышение разницы связано с уменьшением чувствительности грунта $K$ нарушению структурньх связей с увеличением плотности.

Начальные коэффициенты пористости ненарушенного и нарушенного сложения, при которьх и давлении 0,2 МПа получаем одинаковые относительные осадки лимноглациальной глины, графически представлены на рис. 3.

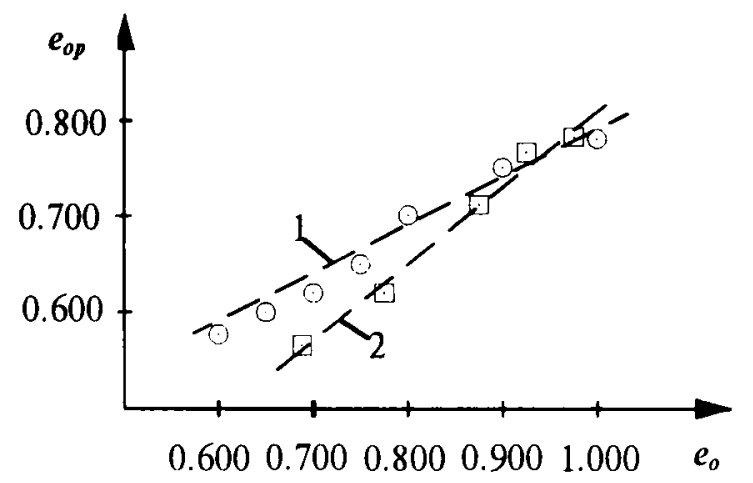

Pис. 3. Зависимость $e_{o p}$ от $e_{0}$ при давлении 0,2 МПа: 1 - при испытании в одометрах; 2 расчетные

Fig 3. $e_{o p}$ dependence upon $e_{0}$ under the loading of 0,2 $\mathrm{MPa}$

Представленная на рис. 3 зависимость применима только при давлении 0,2 МПа. При других давлсния получены другие значения относительной сжимаемости. Как показали проведениыс расчеты, одниаковое миасние относителыной сжимасмости грунта ненарушенного и нарушенного сложения получим только при том давлении, для которого по формуле (15) рассчитан начальный коэффициент пористости. Чтобы получить одинаковое значение относительной сжимаемости грунта ненарушенного и нарушенного сложения при другом давлении, следует рассчитать соответственно и другой начальный коэффициент пористости для гругта нарушенного сложения. Например, чтобы получить одинаковое значение относительной сжимаемости при давлении 0,2 МПа для лимноглациальной глины пенарушенного сложсния с начальным хоэффициентом пористости $e_{0}=0,925$, следует иметь значение начального коэффициента пористости глины нарушенюго сложения $e_{o p}=0,766$, а при давлснии 0,3 МПа - $e_{o p}=$ 0,853 и соответственно при давлении $0,4 \mathrm{MПа}-$ $e_{o p}=0,881$ и давлении $0,5 \mathrm{MПа}-e_{o p}=0,888$.

Следовательно, чем больше давление, тем выне значение начального коэффициента пористости грунта нарушенного сложения, при котором получаем одинаковую относительную сжимаемость. Это можно объяснить тем, тго с увеличением давления болыше нарушаются структурные связи глинистого грунга ненарушенного сложения и по степени нарушения приближаются к грунгу нарушенного сложения.

Значения коэффициегта компрессии $C_{c}$ для грунта нарушенного сложения меняются в зависимости от значения начального коэффициента пористости, соответствснио меняется и згачение соотношения коэффициегта компрессии грунта ненарушенного и нарушенного сложения. Например, для лимноглациальной глины с коэффициентом пористости $e_{0}=0,925$ соотнонение коэффицисптов компрессии иснарушениого и нарушениого сложения при давлении 0,2 МГІа - 1,48, ири $0,3 \mathrm{MПа} \mathrm{-} \mathrm{1,2,} \mathrm{при}$ $0,4 \mathrm{MПа} \mathrm{-} \mathrm{1,15} \mathrm{и} \mathrm{при} 0,5 \mathrm{MПа} \mathrm{-} \mathrm{1,13.} \mathrm{Анализ}$ показывает, что с увеличенисм давления, при котором достигаются одинаконые относительные деформации грунта нснарушенного и нарушенного сложеиия, графики зависимости коэффициента пористости от цавления в полулогарифмической системе координат сближаются. 


\section{4. Заключение}

Деформации уплотнения глинистого грунта естественного и нарушенного сложения проходят по-разному. На характер сжимаемости оказывают влияние структурные связи, их прочность и степень нарупения этих связей в начальной стадии приложения нагрузки. Как показывают компрессионные испьтания лимноглациальньх глин ненарупенного и нарушен ${ }^{-}$ ного сложения на территории Литвы, их сжимаемость различается в два раза и более. Исследованиями установлено, тто коэффициент относительной сжимаемости для глинистого грунта нарушенного сложения больше по сравнению с грунтом естественного сложения при той же нагрузке.

Теоретические и эксперименталыне исследования похазали, что можно полугить зависимость для определения начального коэффициента пористости глинистого грунта нарушенного сложения, при котором для заданного давления относительная сжимаемость будет приблизительно такой же, ках и для грунта ненарушенного сложения.

При коэффициегте пористости, определенном по формуле (15), относительная сжимаемость глинистого грунта естественного и нарушенного сложения при соответствующей нагрузке будет приблизительно одинаковой. Полученная зависимость (15) дает возможность определить коэффициент пористости, до которото следует уплотнить гругт нарушенного сложения, чтобы при соответствующем значении давления получить ту же относительную сжимаемость грунта естественного сложения.

Экспериментальные исследования лимноглациальной глины в компрессионньх приборах похазали, что при принятом в строительной практике давлении на грунт в 0,2 МПа разница между относительным сжатием образцов нарушенного и ненарушенного сложения увеличивается $c$ увеличением зиачений пачальното коэффициента пористости

Результаты рассчитаниых по формуле (15) и экспериментальньх знатений коэффициснтов пористости грунта нарушенного сложения, при которнх деформации при заданном давлении 0,2 МПа те же, что и для грунта естественного сложения, показывают, тто разница межлу ними составляет от 2 до $10 \%$. С уменынением значешия начальнопо коэффициепта пористости уменьшается разница межлу начальными коэффициентами пористости естественного и нарушенного сложения. Уменьшение этой разницы связано с уменынением гувствительности грунта $\mathrm{k}$ нарушению структурных связей $\mathrm{c}$ увеличением плотности. Одинаковые значения относительной сжимаемости грунта ненарушенного и нарушенного сложения получены только при том давлении, для которого по формуле (15) было определено значение начального коэффициента пористости. Чтобы получить одинаковые значения относительной сжимаемости тругта естественного и нарушеппого сложения при другом давлении, следует определить соответсгвенно начальный коэффициент пористости грунта иарушенного сложения при этом даавлении. Чем больше давление, тем больше значение началыного коэффициента пористости грунта нарушенного сложения, при котором его относительная сжимаемость та же, что и для естественного грунта

\section{Литература}

1. А Аликонис, А. Жедялис. Особенности осадконакопления и их влияние на деформационные свойства лимноглациальиых глин нарушенного и ненарушенного сложения // Инженерные изыскания для стронтельства: Материалы семинара изыскателей Прибалтикн. Вильнюс: Мокслас, 1975, с. 46-55.

2. Строительные нормы и правила. Земляные сооружения. Обшие правила производства и

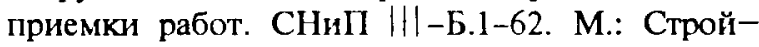
издат, $1967.40 \mathrm{c}$.

3. Строительные нормы и правила. Земляные сооружения, основания и фундаменты. СНиП 3.02.01-87. М.: Стройиздат, 1989. 12 с.

4. Б.И. Далматов. Механика грунтов, основания и фундаменты. М.: Стройиздат, 1981. 319 с.

5. А.А. Леонардас. Основания и фундаменты. М.: Стройиздат, 1968. 504 c.

6. Medrina R. Madhov. et al. 1995. Sentlement of vertical drain treated ground: compression and consolidation of clayey soils-is-Hiroshima'95 (Japan) 10-12 May 1995. Volume 1, p. 695-700.

7. Б.К. Хоу. Основы инженерного грунтоведения. М.: Стройнздат, 1966. $460 \mathrm{c}$.

8. К. Терцаги, Р. Пек. Механика грунтов в инженерной практике. М.: Стройнздат, 1958. 607 с.

9. J. Simkus. Grunty mechanika, pagrindai ir pamatai. V.: Mokslas, 1984. 270 p.

Iteikta 19970417 
NESUARDYTOS IR SUARDYTOS SANDAROS MOLINGOJO GRUNTO SUSPAUDŽLAMUMAS

\section{A. Alikonis}

S a n tra u a

Molingieji gruntai dèl jų geologiniu susiklostymo sąlygu turi struktūrinius ryšius. Suardžius grunto struktūrinius ryšius padidèja suspaudžiamumas. Suardytos sandaros gruntas, nors ir sutankintas iki tankumo, prilygstančio natūralaus grunto tankumui, veikiant apkrovai deformuojasi skirtingai. Statybose pasitaiko atvejų, kai reikia turéti vienodą susispaudžiamumą esant grunto suardytai ir natūraliai sandarai.

Naudojant molingojo grunto su struktūriniu stiprumu kompresines poringumo koeficiento priklausomybes nuo apkrovos pusiau logaritminiame mastelyje, straipsnyje pateikta matematinè priklausomybe் (15) apskaičiuoti suardytos sandaros grunto poringumo koeficientui, kuriam esant santykines deformacijos esant tam tikrai apkrovai prilygsta natūralaus grunto santykinems deformacijoms.

Eksperimentiniai Lietuvos limnoglacialiniy̨ molių tyrimai parode, kad suspaudžiamumo skirtumas tarp suardytos ir nesuardytos sandaros grunto dideja, didèjant pradinio poringumo koeficiento vertei.

Eksperimentiniy tyrimy ir apskaičiuoti pagal (15) formulę rezultatai rodo, kad, pavyzdžiui, esant $0,2 \mathrm{MPa}$ apkrovai skirtumas tarp suardytos sandaros pradiniy poringumo koeficiento verčiu, duodančių vienodas deformacijas, kaip ir natūralaus grunto, mažèja mažèjant pradinei poringumo koeficiento vertei. Skirtumas, gautas sugretinus eksperimento ir skaičiavimo rezultatus, yra nuo $2 \mathrm{iki} 10 \%$. Skirtumo mažèjimas rodo, kad didèjant grunto tankumui mažèja jautrumas natūralios struktūros suardymui.

Apskaičiuotas pagal (15) formulę suardytos sandaros grunto pradinis poringumo koeficientas, kuriam esant turèsime tokias pat, kaip natūralaus grunto, deformacijas, yra skirtas apkrovai, naudotai (15) formulèje. Keičiantis apkrovai keisis ir apskaičiuota pagal (15) formulę pradinio poringumo koeficiento vertè. Didèjant apkrovai didejja ir pradinès poringumo koeficiento vertès, apskaičiuotos pagal (15) formulę. Tai rodo, kad didejjant apkrovai dideja natūralaus grunto struktürinių ryšį suardymo laipsnis, ir jo suspaudžiamumo pobūdis panašus i suardytos sandaros grunto suspaudžiamumą.

\section{COMPRESSION OF THE CLAY SOILS OF NON DESTRUCTED AND DESTRUCTED STRUCTURE}

\section{A. Alikonis}

\section{$\mathrm{Su} \mathrm{m}$ mary}

Clay soils have their structural links according to their geological conditions. Compression increases when the soil structural lincs are destructed. Even if the density of the soils of distructed structure reaches the density of natural soils, though they get deformed differently under loading. Sometimes it is necessary to have equivalent compression of the soils of destructed and natural structure in construction.

The article presents mathematical dependency on how to count a porosity factor of the soils of destructed structure, with its help relative deformations under a given loading come up with relative deformation of natural soils, using dependency of compression porosity factor of structurally rigid soils upon loading in a semi-logarithmic scale. Experimental research into Lithuanian limnoglacial clay soils has showed that increase in the assessment of the initial porosity factor is followed by an increase in difference between the compression of non-destructed and destructed soils. Experimentally obtained and calculated (according to formula 15) results show that, for example, under the loading of $0,2 \mathrm{MPa}$, decrease in the assessment of the initial porosity factor is followed by a decrease in difference between the assessments of the initial porosity factor of destructed structure, giving deformations equivalent to those of natural soils. The difference which occured after experimentally obtained and calculated results were compared-from $2 \%$ to $10 \%$.

The decrease in difference shows that an increase in soil density is followed by a decrease in sensitivity of destructure of its natural structure. The initial porosity factor of the soils of destructed structure, calculated according to formula (15), enables us to have deformations equivalent to those of natural soils and it is provided for the loading used in formula (15). Changes in loading will be followed by changes in the assessment of the initial porosity factor calculated according to formula (15).

The increase in loading is followed by an increase in the initial assessment of the porosity factor. It shows that an increase in loading is followed by an increase in the degree of destruction of structural links of natural soils and its nature of compression comes up with the compression of the soils of destructed structure. Structural rigidity of soil can be determined by intersection of lines $A C$ and $C D$ (Fig 1).

After the natural structure of clity soils has been destructed, part of its structural rigidity remains. Experimental research shows that there is a short interval $\mathrm{AB}$ a small pitch (Fig 2) in a compression curve of limnoglacial kneaded up clay indicating the remaining structural links. According to experimental research, in comparison to natural soils, structural rigidity of the clay soils of destructed structure (kneaded up clay soils) forms a very small part. Therefore when working out engineering tasks connected with construction, we shoned accept that the compression curve of the clay soils of destructed (kneaded up) structure in a semi-logarithmic scale is a line, with its beginning at point $\mathrm{A}$ (Fig 2). It indicates that deformation of destructed soils begins with the initial loading (Fig 1, line 3), whereas considerable deformation of natural soils begins under the loading higher than the structural rigidity of the soil.

Antanas ALIKONIS. Doctor, Associate Professor. Department of Geotechnics. Vilnius Gediminas Technical University. 11 Sauletekio Ave, 2040 Vilnius, Lithuania

In 1968 Doctor (technical sciences). Since 1970 Associate Professor at the Department of Footings and Foundations, during 1980-96 Head of this Department (now Department of Geotechnics of Vilnius Gediminas Technical University). Research visits to Moscow and Dnepropetrovsk. Author and co-author of 3 monographs, over 100 scientific articles, 2 patents, 5 inventions and 14 study guides. Research interests: physical and mechanical properties of soils. 